\title{
Protocol development for minimally processed pomegranate
} arils

\author{
P.K. Amith, C. Mini* and R.V. Manju
}

Department of Processing Technology, College of Agriculture, Kerala Agricultural University, VELLAYANI (KERALA) INDIA

*Author for Correspondence

Research chronicle : Received : 08.04.2015; Revised : 25.04.2015; Accepted : 07.05.2015

\section{SUMMARY :}

Minimally processed pomegranate arils can be prepared by surface sanitization of fruits using 30ppm sodium hypochlorite for 15 minutes followed by rind removal, treating the arils with 1 per cent calcium chloride for 10 minutes and refrigerated storage after packaging in aluminium tray covered with cling film. Samples were acceptable to the sensory panel even at the end of $5^{\text {th }}$ day.

KEY WORDS : Minimal processing, Pomegranate arils, Sodium hypochlorite, Calcium chloride, Packaging

How to cite this paper : Amith, P.K., Mini, C. and Manju, R.V. (2015). Protocol development for minimally processed pomegranate arils. Internat. J. Proc. \& Post Harvest Technol., 6 (1) : 62-68. 